\title{
Lymph nodes in the head and neck cancer: would diffusion-weighted magnetic resonance imaging solve the diagnostic dilemma?
}

\author{
Dalia K. Serour *iD, Bahaa Eldin Mahmoud, Bassant Daragily and Shaima Fattouh Elkholy
}

\begin{abstract}
Background: Head and neck cancer has been labeled as the fifth most common cancer. Lymph node (LN) metastases were reported as the most important predatory factor for diagnosis and selection of suitable treatment. Diffusion-weighted (DW) magnetic resonance (MR) imaging is a very important tool that gives quantitative data in several compartments. This work aims to evaluate the diagnostic value of diffusion-weighted as a part of the magnetic resonance imaging in patients with head and neck cancer to allow differentiation of lymph nodes, cancer staging, assessment of recurrence, and evaluation of the effects of oncologic therapy.

Results: The size of pathologically proven benign LNs ranged from 1 to $3 \mathrm{~cm}(1.71 \pm 0.724)$ and malignant LNs ranged from 1.1 to $5.6 \mathrm{~cm}(2.54 \pm 0.92)(P=0.0103)$. The ADC value for benign $L N s$ ranged from $1.26 \times 10^{-3}$ to 2.49 $\times 10^{-3}$ (mean $\left.1.98 \times 10^{-3} \pm 0.32 \times 10^{-3}\right)$, and malignant LNs from $0.608 \times 10^{-3}$ to $2.1 \times 10^{-3}$ (mean $0.971 \times 10^{-3} \pm$ $\left.0.305 \times 10^{-3}\right)(P<0.001)$ with sensitivity and a specificity of $94 \%$ and $100 \%$ respectively. The ADC value for metastatic LNs ranged from $0.70 \times 10^{-3}$ to $2.10 \times 10^{-3}\left(1.08 \times 10^{-3} \pm 0.31 \times 10^{-3}\right)$ while lymphomatous nodes ranged $0.608 \times 10^{-3}$ to $1.16 \times 10^{-3}\left(0.78 \times 10^{-3} \pm 0.17 \times 10^{-3}\right)$. In this study, a significant statistical difference was also observed between the ADC value of the SCC and lymphomatous LN $(P=0.0034)$ with sensitivity and a specificity of $90 \%$ and $75 \%$ respectively.

Conclusion: Diffusion-weighted MR imaging is an effective assist in differentiating benign and malignant lymph nodes. It acts as an indicator for recovery or recurrence after chemotherapy and radiotherapy.
\end{abstract}

Keywords: Head and neck cancer, Lymph nodes, DW-MRI, ADC, Benign, Malignant

\section{Background}

Lymph nodes are widely distributed, and our body has about 800 lymph nodes, about 300 are found in the neck [1]. Enlarged abnormal cervical lymph nodes are indicator for several pathological conditions including tumors, infection, and inflammation [2]. Cervical lymphadenopathy is a term to describe the conditions in which lymph nodes become abnormal

* Correspondence: daliakhaled80@yahoo.com

Department of Diagnostic Radiology, Cairo University, Giza, Egypt in size (measuring more than $1 \mathrm{~cm}$ in diameter), consistency, and number [3, 4]. DWI is recognized as a sensitive marker in distinguishing between benign and malignant head and neck cancer, treatment protocol, and follow-up $[5,6]$.

Tumors in the head and neck are including cancers in various anatomical sites including tumors of the oral cavity, nasopharynx, paranasal sinuses, and larynx [7]. Globally, tumors in the head and neck are recognized as one of the top five tumor types. They are accounting for about 3 to $4 \%$ of the overall malignancies. So far, tumors in the head and neck are responsible for more than 700, 
000 cases and more than 350,000 deaths annually $[8,9]$. About $95 \%$ of head and neck cancer begins in squamous cells and known as head and neck squamous cell carcinoma (HNSCC). Alcohol and tobacco are the major risk factors for causing and developing this type of tumor; recently, the Epstein-Barr virus (EBV) and the human papillomavirus (HPV) are also considered other risk factors for the nasopharyngeal and oropharyngeal cancers respectively $[7,10]$. Computed tomography $(\mathrm{CT})$, routine magnetic resonance imaging, and laryngoscopy are the most commonly used diagnostic techniques for that type of cancer [11]. MRI sequences provided precise data regarding tumor size, site, and the head and cancer morphology. The diffusion-weighted imaging as a part of the MRI technique being a non-invasive tool without the definite need for administration of intravenous contrast agent had provided a reliable ability in the differentiation between the benign and malignant tissues [12].

The main objective of this study was to evaluate the role of diffusion-weighted magnetic resonance imaging in differentiating between the benign and the malignant lymph nodes in patients with head and neck malignancy as well as to evaluate its role as regards the cancer staging, recurrence, as well as evaluation of the effects of oncologic therapy.

\section{Methods}

This study was conducted on 40 patients referred to the radiodiagnosis and imaging department of our institution, between March and September 2018. The patients included in this study were from the outpatient clinics suffering from palpable cervical lymph nodes with unknown primary malignancy or having a known head and neck cancer. This study is IRB approved with a provided written consent given by all patients before proceeding with examination. The exclusion criteria were nonconfirmed histopathological results and absolute contraindications to MRI such as cardiac pacemakers.

The full socio-demographic and clinical data including age, sex, and general examination including local head and neck examination as well as the laboratory biochemical parameters such as kidney function parameters were all recorded.

All MR examinations were acquired by a $1.5-\mathrm{T}$ wholebody system Philips machine. All the patients were scanned in the supine position utilizing a head and neck surface coil for both the conventional imaging and diffusion-weighted MR imaging. The conducted sequences included the axial and coronal T2-weighted fast spin-echo sequences, followed by axial T1-weighted pre and post-fat-suppression fast spin-echo sequences with given parameters summarized in Table 1.

The diffusion acquisition was obtained using $b$ values 0,500 , and $1000 \mathrm{~s} / \mathrm{mm}^{2}$. We used a high $b$ value of 1000 $\mathrm{s} / \mathrm{mm}^{2}$ to give an accurate assessment at sufficiently high signal-to-noise ratios. The diffusion-weighted images were generated by single-shot echo-planar imaging spinecho technique with the given parameters: TR/TE, 2000/ 50-60; slice thickness, $5 \mathrm{~mm}$; matrix, $256 \times 256$; FOV, $220 \mathrm{~mm}$; and flip angle, $90^{\circ}$. The ADC map was generated by using the acquired images, and the apparent diffusion coefficient (ADC) was calculated monoexponentially via the scanner software.

The post-contrast sequence images were obtained after Gadoteric acid IV injection given at a rate of $2 \mathrm{ml} /$ s. Post-contrast T1-weighted imaging with fat suppression was performed in the axial and coronal planes.

The lymph nodes were assessed based on the internationally accredited standards for the assessment of the anatomical imaging data. Firstly, we detected the anatomical location of enlarged lymph nodes and characterized them by the numerical grouping system. Then, the size and morphological characteristics of lymph nodes as regard to their parenchymal homogeneity and contrast enhancement were reported. The DW images with their corresponding ADC maps were carefully evaluated in concurrence. Through the obtained $b$ value of $0 \mathrm{~s} / \mathrm{mm}^{2}$ images, the lymph nodes were adequately localized. Multiple (2-3) regions of interests (ROIs) were put over the lymph nodes that were depicted on the $b$ value 0 images based on visual assessment in order to obtain quantitative assessment; those regions were automatically transferred to the other $b$ value images. For all solid lymph nodes, the regions of interest were put anywhere along the center and/or periphery of the examined lymph node. For other nodes showing mixed solid and necrotic components, the regions of interest was put on the solid portion. The mean ADC value of all the examined ROIs was used for the analysis and was known to be the mean ADC for the lesion.

Finally, the radiologic findings were correlated with the histopathologic results as a reference standard. Histopathologic analysis was done in all patients (3 patients underwent excisional biopsy while 37 patients underwent fine-needle aspiration cytology (FNAC)).

The optimal ADC threshold with $b$ values 0 and 1000 for discriminating the benign from the malignant lymph nodes was established via using receiver operating characteristic analysis. The sensitivity and specificity of the ADC with $b$ values 0 and 1000 were subsequently calculated.

The provided data was further analyzed via the Statistical Package for Social Sciences (SPSS) software. $P<0.05$ was regarded as indicating a significant difference.

\section{Results}

Among the study population, 22 (55\%) were males and $18(45 \%)$ were females, their ages ranged between 
Table 1 MR imaging parameters

\begin{tabular}{llllll}
\hline Parameter & $\begin{array}{l}\text { Axial T2-weighted } \\
\text { imaging }\end{array}$ & $\begin{array}{l}\text { Coronal T2-weighted } \\
\text { imaging }\end{array}$ & $\begin{array}{l}\text { Axial T1-weighted } \\
\text { imaging }\end{array}$ & $\begin{array}{l}\text { DW } \\
\text { imaging }\end{array}$ & $\begin{array}{l}\text { Contrast-enhanced axial and } \\
\text { coronal T1-WI with fat suppression }\end{array}$ \\
\hline TR (ms) & $2500-4500$ & 3850 & $400-650$ & 2000 & $740-775$ \\
TE (ms) & 80 & 80 & 14 & $50-60$ & $8-12$ \\
Flip angle $\left(^{\circ}\right)$ & 90 & 90 & 90 & 90 & 15 \\
Section thickness (mm) & 5 & 5 & 5 & 5 & 5 \\
Intersection gap (mm) & No & No & No & No & No \\
Matrix & $320 \times 224$ & $288 \times 192$ & $256 \times 192$ & $256 \times 256$ & $288 \times 224$ \\
Field of view (mm) & 220 & 220 & 220 & 220 & 220 \\
Voxel size & RL 0.9, AP 1.1 & RL 0.9, AP 1.1 & RL 0.9, AP 1.1 & RL 0.9, AP 1.1 & RL 0.9, AP 1.1 \\
No. of signals acquired & 4 & 4 & 4 & 4 & 4 \\
\hline
\end{tabular}

11 and 67 years (mean age $39.75 \pm 17.6$ ), and a total pathological lymph nodal mean size of $2.21 \pm 0.95 \mathrm{~cm}$ (range $1-5.6 \mathrm{~cm}$ ). The clinical presentation of the study patients revealed that $17(43 \%)$ patients who came with appreciable cervical lymph nodes had no identified primary and had US neck or CT prior to their MRI study; 19 (47\%) patients who reported to have head and neck cancer had come for staging and treatment preparation while $4(10 \%)$ patients who came for their post-operative follow-up (thyroidectomy and radioactive iodine or hemiglossectomy) had undergone neck US prior to MRI neck examination.

\section{Histopathological analysis}

Figure 1 shows the subgroups of lymph nodes according to the histopathology. The image evaluation showed that 10 cases were pathologically proven to be benign lymphadenopathy with the size ranged between 1 and $3 \mathrm{~cm} \mathrm{(1.71} \pm 0.724)$, including acute reactive lymphadenitis, chronic granulomatous, chronic non-specific inflammation, and hyperplasia of the reactive lymphoid tissue, and 30 malignant lymph nodes; the malignant nodes measured between 1.1 and $5.6 \mathrm{~cm}(2.54 \pm 0.92)$ include 20 metastatic LNs from head and neck malignancy and 10 primary lymphomas; the difference between the benign and malignant nodes as regard their size was statistically significant $(P$ value $=0.0103)($ Fig. 2$)$.

\section{Parenchymal architecture}

Table 2 showed the parenchymal architecture of malignant and benign lymphadenopathy. The ADC value for benign LNs ranged between $1.26 \times 10^{-3}$ and $2.49 \times 10^{-3}$ $\left(1.98 \times 10^{-3} \pm 0.32 \times 10^{-3}\right)$. The ADC value for malignant LNs ranged between $0.608 \times 10^{-3}$ and $2.1 \times 10^{-3}$ $\left(0.971 \times 10^{-3} \pm 0.305 \times 10^{-} 3\right)$. There was a statistically significant difference between the benign and malignant nodes as regards their ADC with $P<0.001$ (Fig. 3).

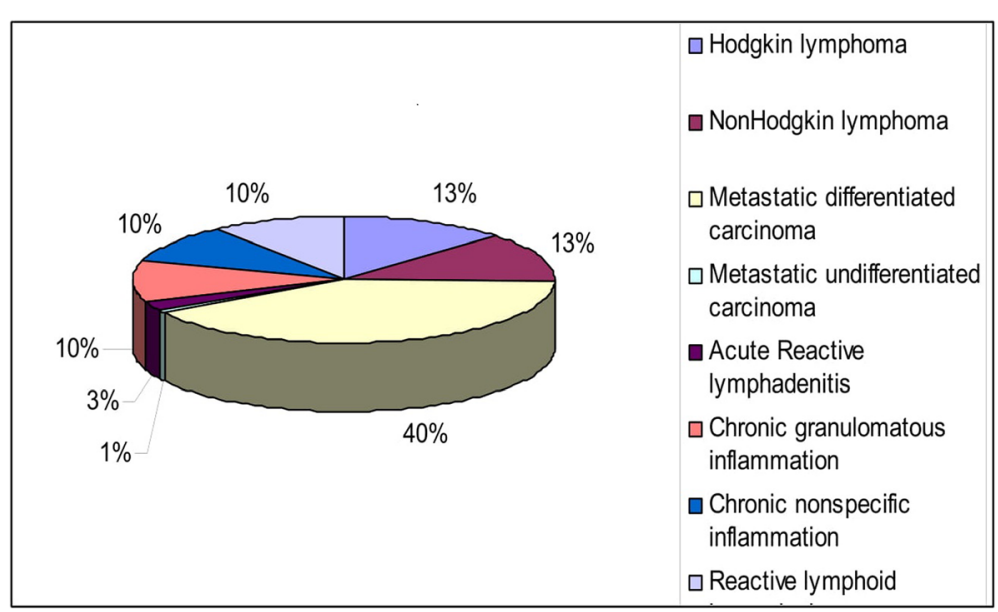

Fig. 1 Pie chart showing the subgroups of lymph nodes according to the histopathology 


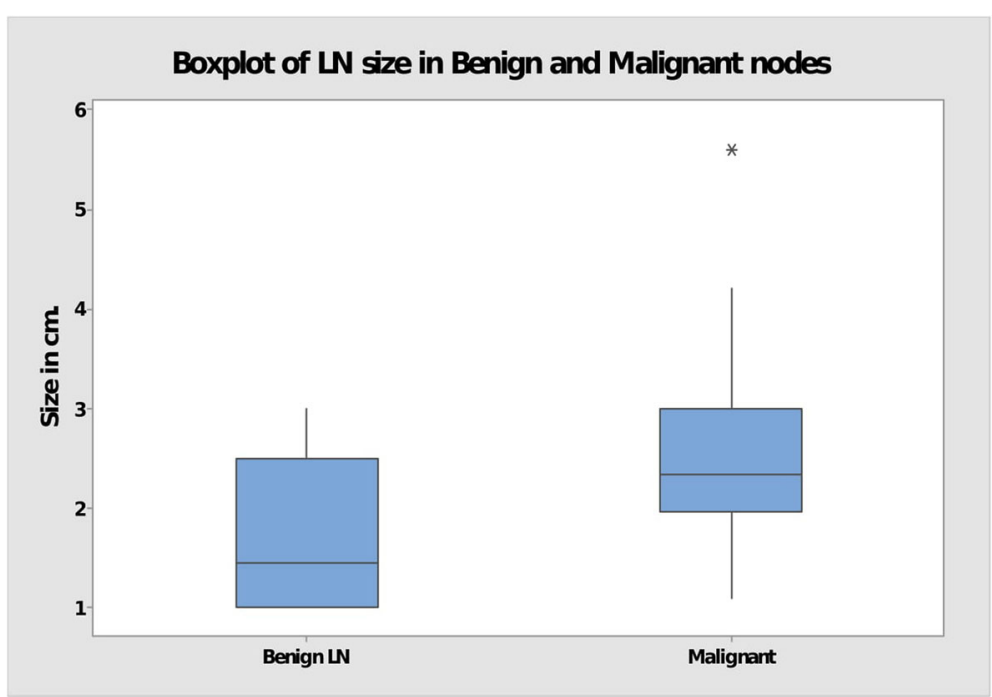

Fig. 2 Boxplot of LN size in benign versus malignant lymph nodes

Further analysis of the ADC values in patients with metastatic LNs and lymphoma revealed that the ADC value for metastatic LNs ranged between $0.70 \times 10^{-3}$ and $2.10 \times 10^{-3}\left(1.08 \times 10^{-3} \pm 0.31 \times 10^{-3}\right)$. The ADC value for lymphomatous LNs ranged between $0.608 \times$ $10^{-3}$ and $1.16 \times 10^{-3}\left(0.78 \times 10^{-3} \pm 0.17 \times 10^{-3}\right)$. The discrepancy was statistically significant with $P=0.0034$ (Fig. 4).

\section{Receiver operating characteristic analysis}

Figure 5 shows the analysis of the ROC curve for ADC values in benign vs. malignant LNs revealed a sensitivity of $90.00 \%$ with $100 \%$ specificity for discrimination between the benign and malignant nodes for ADC value $\leq 1.3 \times 10^{-3}$. ROC curve analysis of ADC values in metastasis vs. lymphoma revealed a sensitivity of $90.00 \%$ with $75 \%$ specificity for differentiation between the metastatic and lymphomatous nodes for ADC value $\leq$ $0.9 \times 10^{-3}$. Figures $6,7,8$, and 9 showed 4 different cases with its final diagnosis and ADC values.

\section{Discussion}

DW-MRI (diffusion-weighted magnetic resonance imaging) is an effective non-invasive imaging technique for tissue characterization. DWI has been considered as a cancer biomarker and could distinguish benign from malignant tumors [13]. Our research aimed to establish the diagnostic validity of the diffusionweighted magnetic resonance imaging for the distinction between benign and malignant lymph nodes via comparing the ADC values, as solving out this diagnostic problem is mandatory for the management of the patients.

Our study revealed that the prevalence of tumors in the head and neck was higher in males (55\%) than females $(45 \%)$ without significant differences, in agreement with Lambert et al. [14] who reported that males are highly affected than females, but with a significant difference, with a ratio ranging from 2 to 4 folds. Our study results showed that Hodgkin disease incidence is higher in young age groups, although the prevalence of non-Hodgkin disease among the elderly population was

Table 2 The parenchymal architecture of malignant and benign lymphadenopathy

\begin{tabular}{llll}
\hline Parenchymal architecture & & Malignant & Benign \\
\hline Nodes exhibited & Homogenous & $25(83.33 \%)$ & $10(100 \%)$ \\
& Heterogeneous & $5(16.67 \%)$ & $0(0 \%)$ \\
Lymph node groups affection & Multiple & $23(76.67 \%)$ & $7(70 \%)$ \\
Nodes degeneration & Single & $7(23.33 \%)$ & $3(30 \%)$ \\
& Exhibited internal degeneration with breaking down & $12(40 \%)$ & $2(20 \%)$ \\
\hline
\end{tabular}


Boxplot of ADC values in Benign vs. Malignant LNs

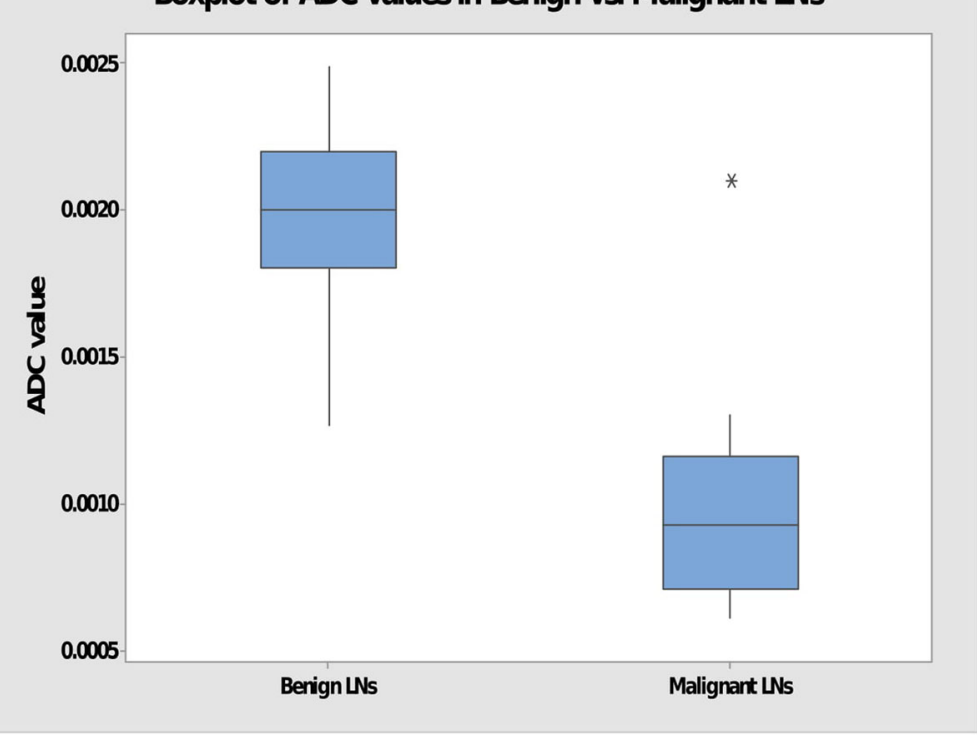

Fig. 3 Boxplot of ADC values in benign versus malignant lymph nodes

higher, with no significant difference. Our study findings are in line with previous studies which reported that Hodgkin lymphoma is higher in younger age groups [15-17].

Our analysis included 9 nodes less than $1 \mathrm{~cm}$ in their shortest axis diameter; $3 / 9$ were metastatic and showed a pattern of restriction on DWIs and opposing low ADC value. On the other hand, these 9 nodes displayed no definite morphological characteristics of malignancy, such as necrosis and ill-defined margins in the conventional MRI sequences, and classification of metastatic nodes would have been very unlikely, in agreement with

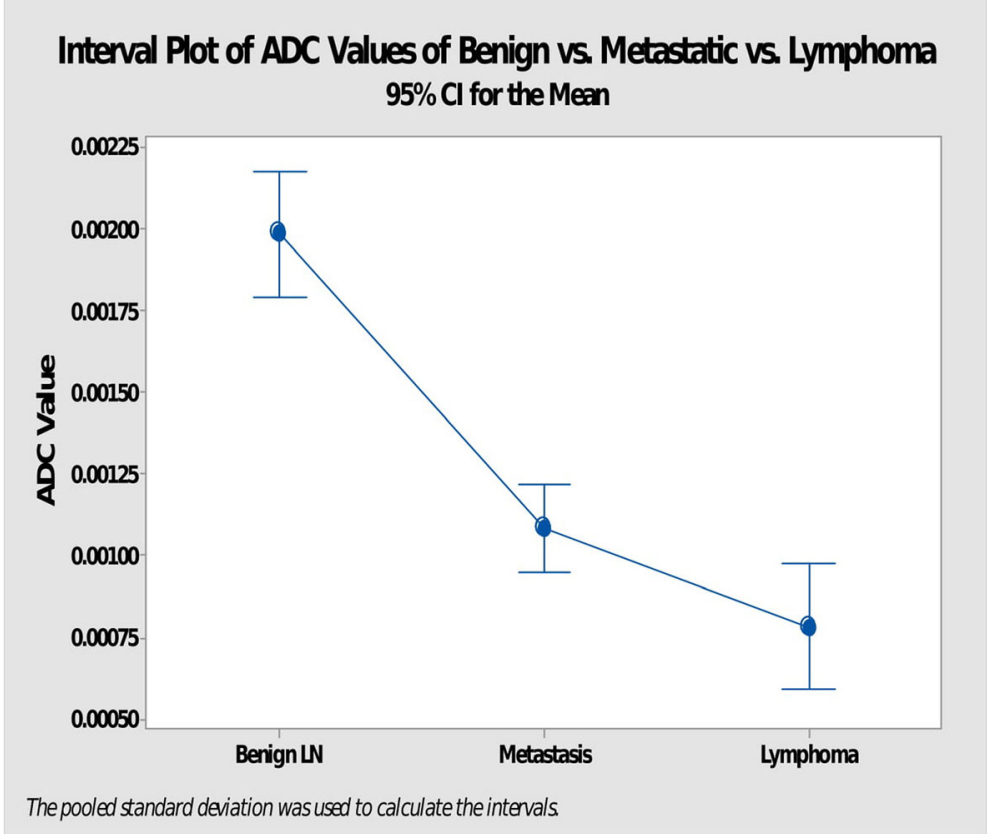

Fig. 4 Interval plot of ADC values of benign LN, metastatic LN, and lymphomatous LN 


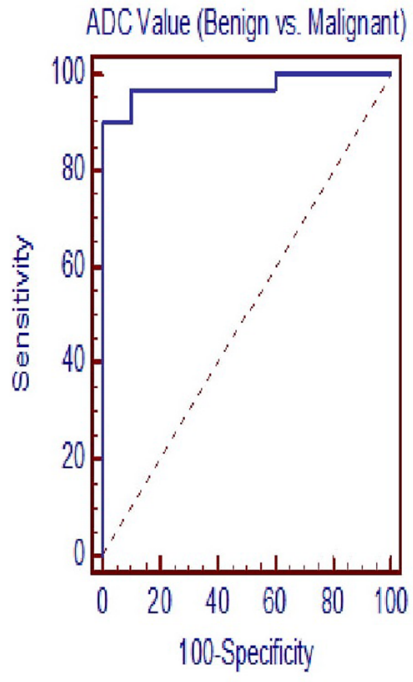

A

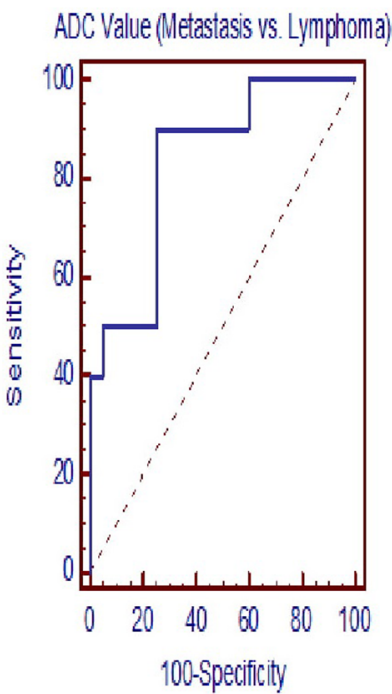

B

Fig. 5 a ROC curve analysis for ADC values in benign versus malignant $L N$. b ROC curve analysis for ADC values in metastatic versus lymphomatous LN

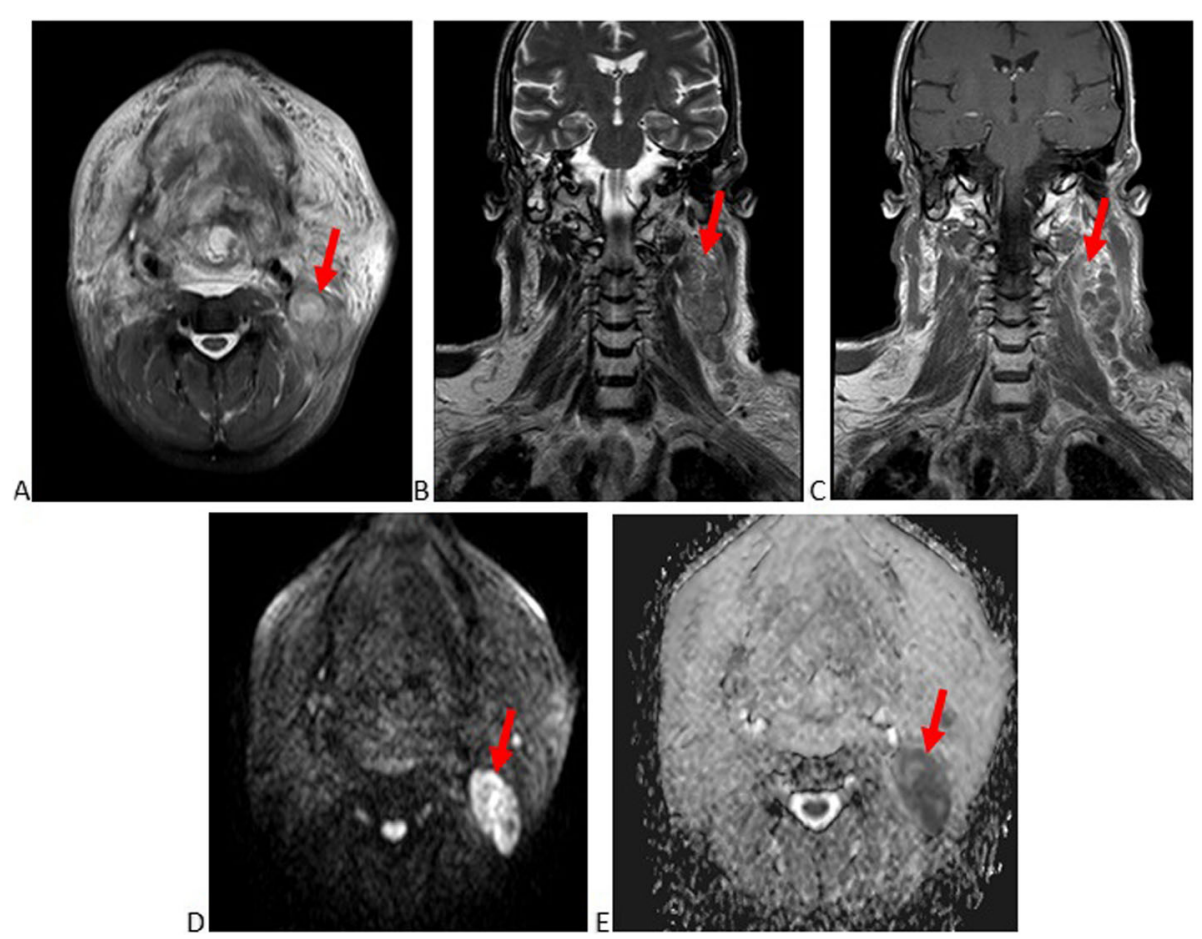

Fig. 6 Fifty-five-year-old male with a known history of laryngeal carcinoma a axial T2, b coronal T2 WIs showing multiple enlarged left deep cervical and supraclavicular lymph nodes exhibiting intermediate to high T2 signal. c Post-contrast coronal T1 Wls showing heterogeneous contrast uptake and breaking down. d DWls b 1000 and e ADC map showing hyperintense LNs in diffusion images corresponding to low signal in $A D C$ map with an $A D C$ value varying from $0.893 \times 10^{-3}$ to $0.927 \times 10^{-3} \mathrm{~mm}^{2} / \mathrm{s}$; the possibility of metastatic nodal deposits is considered which was proven by biopsy 

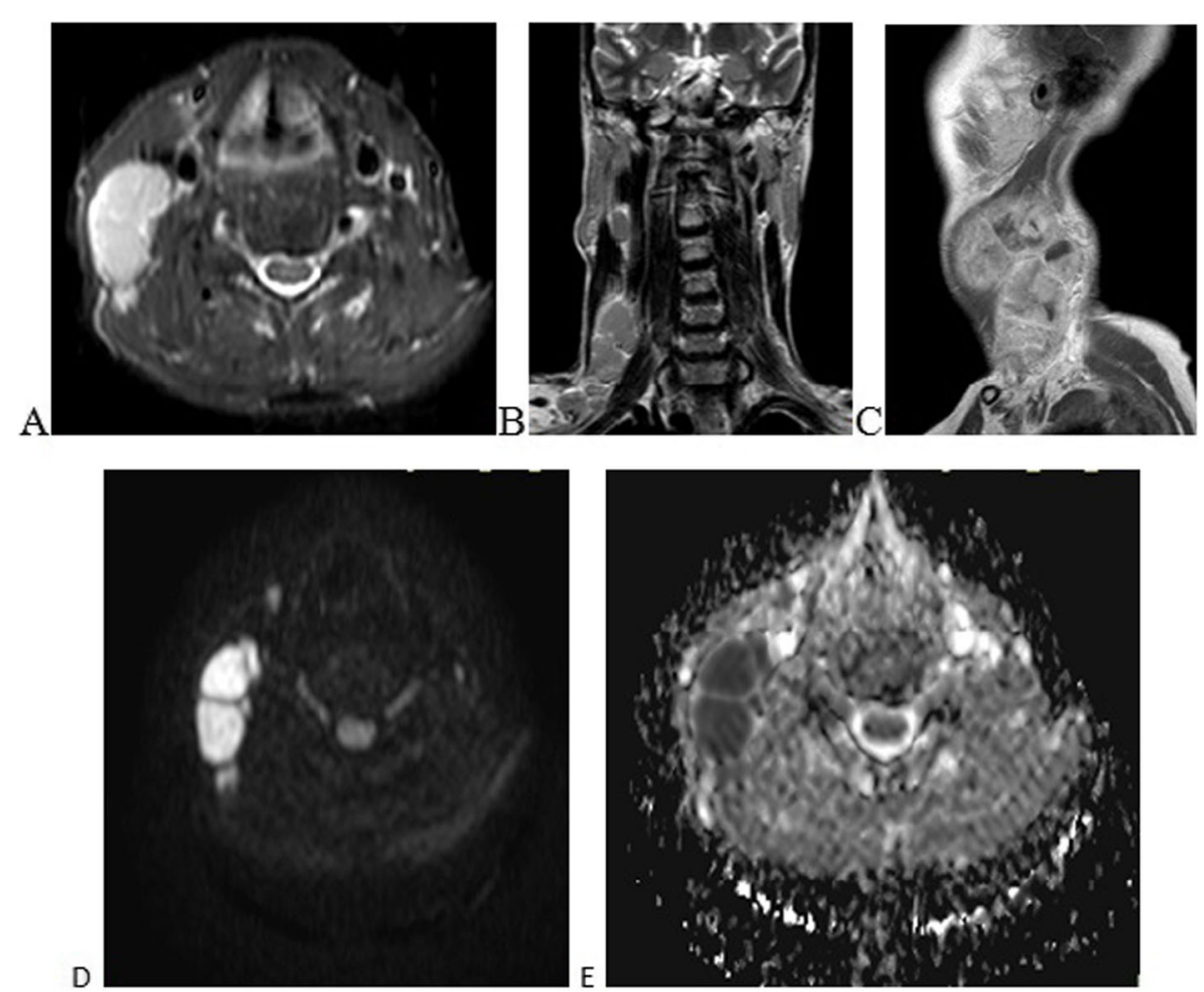

Fig. 7 Forty-five-year-old male, known case of non-Hodgkin lymphoma with enlarged right deep cervical lymph nodes. a Axial STIR WIs and $\mathbf{b}$ coronal T2 Wls showing high signal of the enlarged nodes. c Post-contrast sagittal T1 Wls showing heterogeneous contrast uptake. $\mathbf{d}$ DWls $b$ 1000 and e ADC map showing hyperintense LNs in diffusion Wls corresponding to low signal in ADC map, with an ADC value of $0.723 \times 10^{-3}$ $\mathrm{mm}^{2} / \mathrm{s}$; the possibility of lymphomatous nodal infiltrate was considered and proven by biopsy

ElSaid et al. [18] who reported that all metastatic lymph nodes less than $1 \mathrm{~cm}$ were missed due to anatomical MR imaging criteria based on size.

In the present study, on the contralateral side of the primary tumor, $1 / 3$ metastatic differentiated squamous cell carcinoma lymph nodes $(<1 \mathrm{~cm})$ were found, in agreement with Vandecaveye et al. [19] and ElSaid et al. [18] who reported the degree to which DWI changes nodal differentiation efficacy via depicting subcentimetric nodal metastases may affect the clinical management. Our study showed that the pathologically proven malignant lymph nodes (29 out of 30 cases) showed increased signal in $b 1000$, and low signal in the corresponding ADC maps, the inflammatory diseases (5 out of 6 cases), and reactive lymphoid hyperplasia (4 out of 4 cases) showed signal intensity reduction for increased $b$ values $(b=1000)$ and intermediate signal intensity on ADC maps representing facilitated diffusion. Our study findings agreeing with Youssef et al. [20] and Abou khadrah and Imam [12] that the DWI with ADC mapping were useful as non-invasive tools for distinguishing between the benign and malignant solid head and neck lesions by using $b$ values 800 and 1000 . The malignant lymph nodes in our sample had significantly lower ADCs than benign lymph nodes. The ADC measurements of benign and malignant lymph nodes varied considerably with a $P<0.001$, these results agree with Youssef et al. [20]. In our research, the mean ADC value of the 30 malignant lymph nodes was $0.971 \pm$ $0.305 \times 10^{-3} \mathrm{~mm}^{2} / \mathrm{s}$, while on the other hand, the mean ADC value of the 10 benign lymph nodes was $1.98 \pm$ $0.33 \pm 3 \mathrm{~mm}^{2} / \mathrm{s}$ with the threshold ADC value for separating malignant from benign nodes obtained from the receiver characteristic analysis being $1.30 \times 10^{-3}$ $\mathrm{mm}^{2} / \mathrm{s}$ with $94 \%$ sensitivity and $100 \%$ specificity. In agreement with Abou khadrah and Imam [12] who recorded 94\% accuracy in characterizing the metastatic lymph nodes using a threshold of $1.0210^{-3} \mathrm{~mm}^{2} / \mathrm{s}$. The mean ADC values recorded for benign and metastatic lymph nodes were $1.24 \pm 0.1610^{-3} \mathrm{~mm}^{2} / \mathrm{s}$ and $0.78 \pm$ $0.0910^{-3} \mathrm{~mm}^{2} / \mathrm{s}$ respectively.

In our research, malignant lymph nodes had been subdivided into subgroups of metastatic carcinoma and lymphoma based upon the histopathology. An attempt was made to distinguish between them according to their ADC values. The mean ADC value for metastatic 

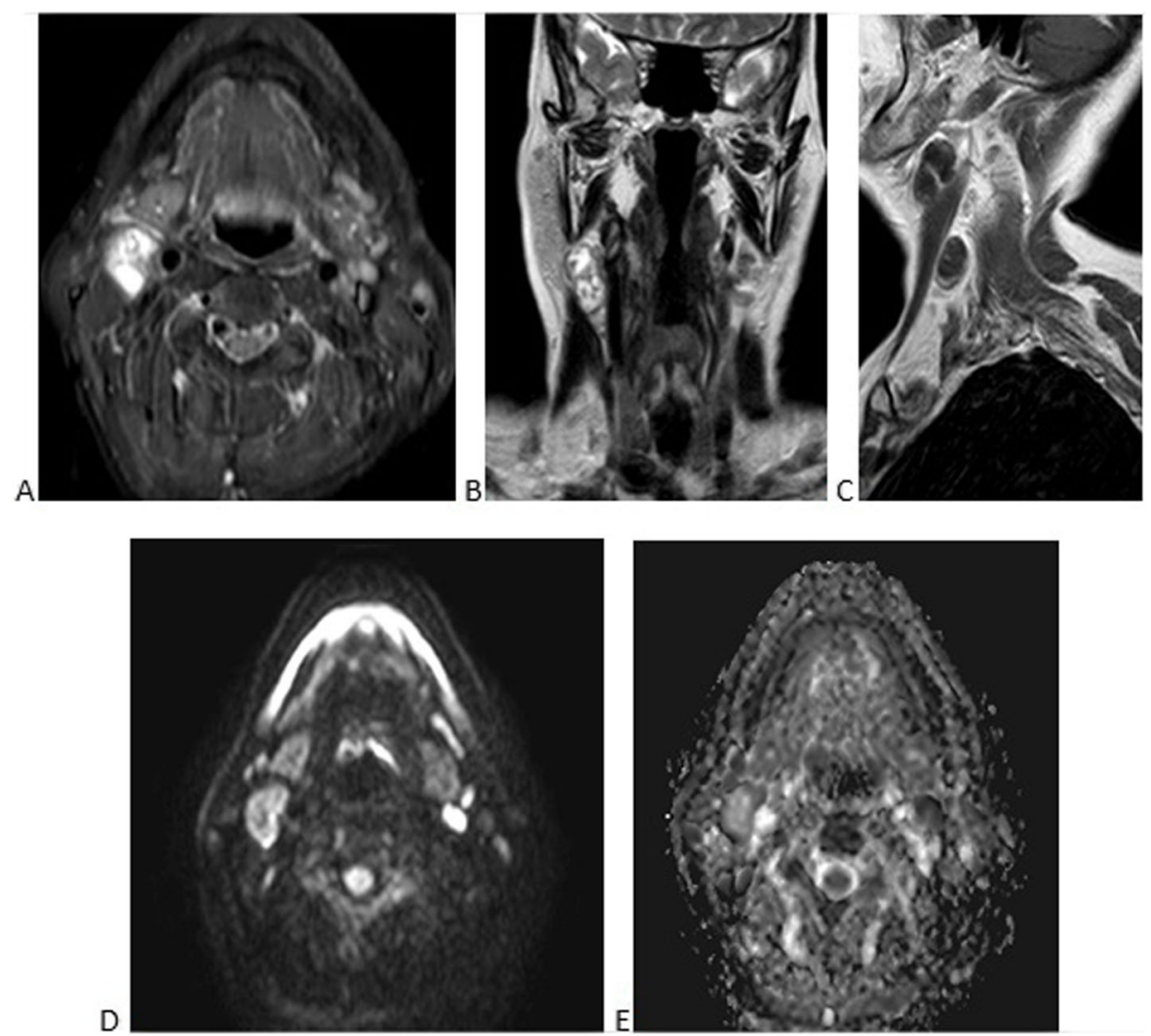

Fig. 8 Sixty-year-old female known case of squamous cell carcinoma of the tongue a axial STIR WIs and $\mathbf{b}$ coronal T2 WIs showing few enlarged right cervical lymph nodes with high T2 and STIR signal. c Post-contrast sagittal T1 WIs showing heterogeneous contrast uptake and a large area of breaking down. $\mathbf{d}$ DWIs $b 1000$ and e ADC map showing hyperintense LNs in diffusion WIs and corresponding intermediate to low signal in ADC map; with an ADC value of $1.127 \times 10^{-3} \mathrm{~mm}^{2} / \mathrm{s}$; the possibility of metastatic nodal deposits is considered which was proven by biopsy

carcinoma $\left(1.079 \times 10^{-3} \mathrm{~mm}^{2} / \mathrm{s}\right)$ was a little higher than that of the lymphoma $\left(0.781 \times 10^{-3} \mathrm{~mm}^{2} / \mathrm{s}\right)$. The ADC threshold value for metastatic differentiation from lymphomatous lymph nodes obtained from receiver operating characteristic (ROC) analysis was $0.9 \times 10^{-3}$ $\mathrm{mm}^{2} / \mathrm{s}$ with $90 \%$ sensitivity and $75 \%$ specificity,

Thirty-four true-positives and 6 false-positives were shown via statistical data, providing a sensitivity of $100 \%$, and specificity of $85 \%$; these results agree with Usama and Ahmed [21] who reported the same results of the present study.

\section{Limitations of this study}

First, our analysis has some drawbacks, such as being a small cohort study. Also, our statistical tests were carried out on the number of nodes involved, not the number of patients. Second, for several reasons, we did not provide standardized ADCs: (1) As far as we know, the value of using standardized, rather than absolute, ADCs in head and neck imaging at DW was never reported. Unlike the brain, the region of the head and neck is distinguished by an extremely heterogeneous diffusivity of the tissues due to the presence of tissues of distinctly different histological origins. The spine is also the most appropriate reference tissue for normalization. However, echoplanar imaging of the spinal cord is hampered by strong susceptibility influences caused mainly by the osseous elements of the spinal column, which induce additional variability in ADC calculations. (2) The promising results of the current study, obtained using absolute ADCs, may suggest that normalization is not necessary, thus facilitating the implementation of DW imaging into routine clinical practice.

\section{Conclusion}

Our study concluded that diffusion MR imaging may be considered a fundamental supporting method in the diagnosis and classification of benign and malignant lymph nodes, can vary to a lesser extent between the forms of malignant lymphadenopathy, and may be recognized as a predictor of post-chemo and radiotherapy improvement and recurrence. 

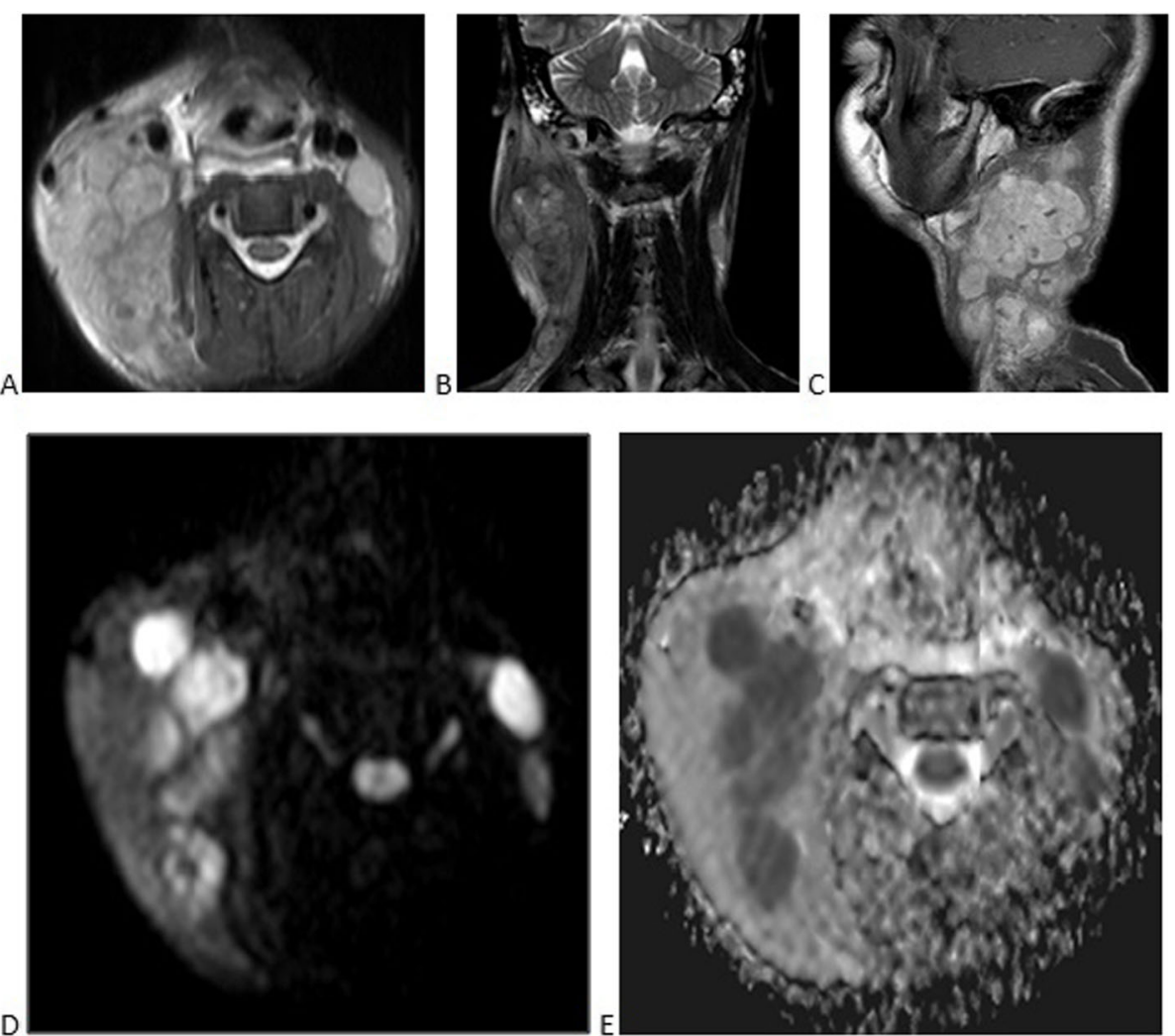

Fig. 9 Thirty-three-year-old patient presenting with bilaterally enlarged deep cervical lymph nodes much more extensive on the right a axial T2 Wls and $\mathbf{b}$ coronal T2 Wls showing intermediate signal of the enlarged lymph nodes. c Post-contrast sagittal T1 Wls showing fair homogenous contrast uptake in the post-contrast sequences. $\mathbf{d}$ DWIs b 1000 and e ADC map showing partially hyperintense LNs in diffusion images corresponding to low signal in ADC map, with an ADC value of $1.3 \times 10^{-3} \mathrm{~mm}^{2} / \mathrm{s}$. The biopsy was negative for metastatic nodal deposits, proven to be benign lymphadenopathy of granulomatous nature

\section{Abbreviations}

ADC: Apparent diffusion coefficient; DW: Diffusion weighted; DWl: Diffusionweighted imaging; EBV: Epstein-Barr virus; FNAC: Fine-needle aspiration cytology; HNSCC: Head and neck squamous cell carcinoma; HPV: Human papillomavirus; IRB: Institutional review board; LN: Lymph node;

MRI: Magnetic resonance imaging; ROC: Receiver operating characteristic; ROI: Region of interest

\section{Acknowledgements}

Not applicable.

\section{Authors' contributions}

D.K.S. puts the idea of the study. MRI assessment and performed the statistical analysis. B.E.M participated in the study design and MRI assessment. B.D participated in data collection and clinical assessment of the patients. S.F.E is the editor of the manuscript. Participation in the study design, performed the MRI assessment. All authors read and approved the final manuscript.

\section{Funding}

Not applicable (no funding)

\section{Availability of data and materials}

All the datasets used and analyzed in this study are available with the corresponding author on reasonable request.

\section{Competing interest}

The authors declare that they have no financial or non-financial competing interest.

\section{Ethics approval and consent to participate}

Written informed consent was signed by all patients before the MRI examination. The study is approved by the medical committee of the faculty of medicine Cairo University in December 2017. Reference number not available.

\section{Consent for publication}

All adult patients included in this research ( $\geq 18$ years of age) gave written informed consent to publish the data contained within this study. If the patient was younger than 18 years or unconscious and consent for publication was requested, written informed consent for the publication of data was given by his/her parent or legal guardian.

Received: 27 May 2020 Accepted: 8 September 2020

Published online: 17 September 2020

\section{References}

1. Chen C-C, Lin J-C, Chen K-W (2015) Lymph node ratio as a prognostic factor in head and neck cancer patients. Radiat Oncol 10(1)

2. Shrivastava, Jyoti. (2019): Spectrum of lesions of superficial lymph nodes on FNAC: a simple, effective tool for diagnosis. 5. 161-163.

3. Anne R Wilkinson, Sadhana D Mahore, Sabiha A. Maimoon (2012): FNAC in the diagnosis of lymph node malignancies: a simple and sensitive tool. Indian J Med Paediatr Oncol 2012; 33(1):21-24.

4. Shahrad Mohseni MD, Abolfazl Shojaiefard MD, Zhamak Khorgami MD, Shahriar Alinejad MD, Ali Ghorbani MD, and Ali Ghafouri MD (2014): Peripheral lymphadenopathy: approach and diagnostic tools, Iran. J Med Sci. 2014 Mar; v 39(2 Suppl): 158-170 
5. Dawood HA, Hassan TA, Mohey N (2014) Value of combined real time sonoelastography and apparent diffusion coefficient value measurement in differentiation of enlarged neck lymph nodes. Egypt J Radiol Nucl Med 45: 387-394

6. Ali TF, El Hariri MA (2017) Combined diffusion-weighted MRI and MR spectroscopy: feasibility to improve the MRI capability in differentiation between benign and malignant neck lymphadenopathy. Egypt J Radiol Nucl Med 48:97-106

7. Aboagye E, Agyemang-Yeboah F, Duduyemi BM, Obirikorang C (2019) Human papillomavirus detection in head and neck squamous cell carcinomas at a tertiary hospital in Sub-Saharan Africa. Sci World J 2019:1-6

8. Bray F, Ferlay J, Soerjomataram I, Siegel RL, Torre LA, et al. (2018): Global cancer statistics 2018: GLOBOCAN estimates of incidence and mortality worldwide for 36 cancers in 185 countries. CA Cancer J Clin 2018; 68:394-424.

9. Alamolhoda F, Faeghi F, Bakhshandeh M, Ahmadi A, Sanei Taheri M, Aabbasi S (2019) Diagnostic value of diffusion weighted magnetic resonance imaging in evaluation of metastatic neck lymph nodes in head and neck cancer: a sample of Iranian patient. Asian Pacific journal of cancer prevention: APJCP 20(6):1789-1795

10. Wołącewicz M, Becht R, Grywalska E, Niedźwiedzka-Rystwej P (2020) Herpesviruses in head and neck cancers. Viruses 12(2):172

11. Zhang, S., Zhou, S., Shang, D., Bao, Y., Ruan, L., \& Wu, T. (2018): The diagnostic role of diffusion-weighted magnetic resonance imaging in hypopharyngeal carcinoma.

12. Abou khadrah RS, Imam HH (2019) Multiple b values of diffusion-weighted magnetic resonance imaging in evaluation of solid head and neck masses. Egypt J Radiol Nucl Med 50:54 (2019)

13. Sabri YY, Nossair EZB, Assal HH et al (2020) Role of diffusion weighted MRimaging in the evaluation of malignant mediastinal lesions. Egypt J Radiol Nucl Med 51:32

14. Lambert R, Sauvaget C, de Camargo Cancela M, Sankaranarayanan R. (2011): Epidemiology of cancer from the oral cavity and oropharynx. Eur J Gastroenterol Hepatol 2011; 23:633.

15. Punnett A, Tsang RW, Hodgson DC. (2010): Hodgkin lymphoma across the age spectrum: epidemiology, therapy, and late effects. Semin Radiat Oncol 2010; 20:30-44.

16. Ansell SM. (2016): Hodgkin lymphoma: 2016 update on diagnosis, riskstratification, and management. Am J Hematol 2016; 91:434-442.

17. Zhou L, Deng Y, Li N et al (2019) Global, regional, and national burden of Hodgkin lymphoma from 1990 to 2017: estimates from the 2017 Global Burden of Disease study. J Hematol Oncol 12:107 (2019)

18. ElSaid NAE, Nada OMM, Habib YS, Semeisem AR, Khalifa NM (2014) Diagnostic accuracy of diffusion weighted MRI in cervical lymphadenopathy cases correlated with pathology results. The Egyptian Journal of Radiology and Nuclear Medicine 45(4):1115-1125

19. Vandecaveye V, De Keyzer F, Vander Poorten V, Dirix P, Verbeken E, Nuyts S, Hermans R (2009) Head and neck squamous cell carcinoma: value of diffusion-weighted MR imaging for nodal staging. Radiology 251(1):134-146

20. Youssef H, Elzorkany M, Hussein S, Taymour T, Helmy M (2019) Evaluation of mediastinal lymphadenopathy by diffusion weighted MRl; correlation with histopathological results. Advances in Respiratory Medicine 87:175-183

21. Usama Elsaied Ghieda, Ahmed Abdul-Raheem Badr, (2020): Diffusionweighted magnetic resonance imaging in characterization of neck lymph nodes in head and neck cancer, International Journal of Medical Imaging. Vol. 8, No. 1, 2020, pp. 6-15.

\section{Publisher's Note}

Springer Nature remains neutral with regard to jurisdictional claims in published maps and institutional affiliations.

\section{Submit your manuscript to a SpringerOpen ${ }^{\circ}$ journal and benefit from:}

- Convenient online submission

- Rigorous peer review

- Open access: articles freely available online

High visibility within the field

- Retaining the copyright to your article

Submit your next manuscript at $\boldsymbol{\nabla}$ springeropen.com 